\title{
¿Para qué sirve un banco de alimentos? \\ Relaciones con sus entidades beneficiarias en una región del Norte de España
}

\author{
Jorge Coque, Pilar L. González-Torre, Marta García \\ Rodríguez
}

\section{RESUMEN}

Los bancos de alimentos son organizaciones sin ánimo de lucro basadas en voluntariado cuyo objetivo es recuperar y redistribuir excedentes alimenticios entre las personas necesitadas a través de otras entidades. Este estudio se centra en las relaciones de un banco de alimentos con sus organizaciones beneficiarias, que se clasifican en entidades de consumo y entidades de reparto. El trabajo asume una estructura metodológica híbrida cuantitativa-cualitativa, con una primera fase, de carácter exploratorio mediante una encuesta dirigida a todas esas entidades, y una segunda, consistente en un taller participativo para devolución, contraste y profundización de los datos recogidos en la anterior. Los resultados muestran las diferencias entre ambos tipos de entidades en el actual marco de crisis socioeconómica, y sus problemas comunes que se resumen en las dificultades para satisfacer la demanda cuando es muy heterogénea y creciente, y cuando la oferta sigue reglas independientes.

PALABRAS CLAVE: Bancos de alimentos, entidades no lucrativas, entidades de consumo, entidades de reparto, encuesta, investigación-acción participativa, demanda, oferta.

CLAVES ECONLIT: I310, L310, Q180, Q510, R410.

Cómo citar este artículo: COQUE, J., GONZÁLEZ-TORRE, P. \& GARCÍA, M. (2015): ¿Para qué sirve un banco de alimentos? Relaciones con sus entidades beneficiarias en una región del Norte de España", CIRIEC-España, Revista de Economía Pública, Social y Cooperativa, 83, 251-281.

Correspondencia: Jorge Coque, Pilar L. González-Torre, Marta García Rodríguez, Universidad de Oviedo. E-mail de contacto: coque@uniovi.es. 


\title{
À quoi sert une banque alimentaire ? Relations avec ses entités bénéficiaires dans une région du nord de l'Espagne
}

RÉSUMÉ : Les banques alimentaires sont des organisations à but non lucratif fondées sur le bénévolat. Elles ont pour objectif de collecter et redistribuer des excédents alimentaires aux personnes dans le besoin par le biais d'autres entités. Cette étude se concentre sur les relations entre une banque alimentaire et ses organisations bénéficiaires, pour lesquelles on distingue entité de consommation et de répartition. Le travail adopte une structure méthodologique hybride quantitative-qualitative, avec une première phase exploratoire grâce à une enquête à l'intention de toutes ces entités, et une seconde, comprenant un atelier participatif pour le renvoi, la comparaison et l'approfondissement des données collectées lors de la première phase. Les résultats montrent les différences entre les deux types d'entités dans le cadre actuel de la crise socio-économique, ainsi que des problèmes communs qui se résument aux difficultés rencontrées pour répondre à la demande lorsqu'elle est très hétérogène et croissante, ou lorsque l'offre suit des règles indépendantes.

MOTS CLÉ : Banques alimentaires, entités à but non lucratif, entités de consommation, entités de répartition, enquête, recherche-action participative, demande, offre.

\section{What is a food bank for? Relations with beneficiary organizations in a region of northern spain}

\begin{abstract}
Food banks are volunteer-based non-profit organizations whose goal is to recover and redistribute food surpluses to needy people through other organizations. This study focuses on the relationship between a food bank and its beneficiary organizations, which can be classified into food consumption organizations and food distribution organizations. The study adopted a hybrid quantitative-qualitative methodology. The first step was an exploratory survey addressed to all those organizations. The second step consisted in a participatory workshop for returning the survey and contrasting and exploring the data collected in greater depth. The results show the differences between the two types of organization in the framework of the current socio-economic crisis, and their common problems, which can be summarized as the difficulties in satisfying demand when it is very heterogeneous and is growing, and when the supply follows its own rules.
\end{abstract}

KEY WORDS: Food banks, food consumption organizations, food distribution organizations, survey, participative action research, demand, supply. 


\section{1.- Contextualización1}

La crisis global actual afecta directamente a los países industrializados y de forma más indirecta y grave a los países pobres. Una de las consecuencias evidentes es que 925 millones de personas corren riesgo de desnutrición y que la población de 2050 (estimada en unos 9.000 millones de habitantes) requeriría un incremento del $70 \%$ en el abastecimiento de alimentos (FAO, 2011).

En España en particular, el 21,6\% de la población se considera pobre al percibir anualmente ingresos inferiores a 7.040 euros y esta cifra empeora año tras año (INE, 2013). Cuando a la cifra de ingresos se añaden otros indicadores, se confirma esta tendencia negativa: en nuestro país solo una de cada tres personas se encontraba en 2013 en situación de integración plena (ajena a los diferentes círculos de exclusión que van desde la integración precaria o la exclusión moderada hasta la exclusión más severa), esto es, 16,5 puntos más que en 2007 (FOESSA, 2014). En el extremo más débil, el último Informe de la Realidad Social de Cáritas arroja datos alarmantes: la pobreza severa, que incluye tanto malnutrición como desnutrición, alcanza ya a tres millones de personas (Equipo de Estudios Cáritas Española, 2013).

En paralelo a ese panorama de necesidades insatisfechas, cerca de un tercio de los alimentos que se producen cada año para el consumo humano (unos 1.300 millones de toneladas) se pierden o desperdician. El problema del desperdicio de alimentos se acentúa en los países industrializados, donde, en la mayoría de los casos, es originado tanto por los minoristas como por los consumidores, que arrojan alimentos perfectamente comestibles a la basura. En Europa hasta el $50 \%$ de los alimentos sanos se transforman en residuos a lo largo de la cadena agroalimentaria (FAO, 2011).

Como respuesta a esta realidad, los bancos de alimentos son organizaciones sin ánimo de lucro basadas en el voluntariado cuyo objetivo es recuperar excedentes alimenticios y redistribuirlos entre las personas necesitadas (FESBAL, 2015) a través de otras entidades no lucrativas (Schneider, 2013). Sus actividades incluyen, por un lado, la búsqueda y captación de alimentos procedentes de excedentes y donaciones, para su posterior distribución entre las organizaciones necesitadas y entidades sociales benéficas 0 asistenciales (figura 1), y, por otro, la concienciación y sensibilización contra el despilfarro y las desigualdades sociales mediante la captación de voluntariado y recogida de alimentos. Los bancos no se encargan de la entrega directa de la comida a la población necesitada, sino de distribuirla entre instituciones de ayuda social -altruista o autoayuda según los casos-, que tienen contacto con los colectivos más desfavorecidos de la sociedad (FESBAL, 2015).

1.- Este estudio se benefició de una beca dotada por el Ayuntamiento de Gijón a través del Instituto Universitario de Tecnología Industrial de Asturias (IUTA) (proyecto SV-13-GIJÓN-1). También ha sido financiado por un proyecto del Ministerio de Economía y Competitividad (DPI201341469-P). 


\section{Figura 1. Situación de los bancos de alimentos en la cadena logística}

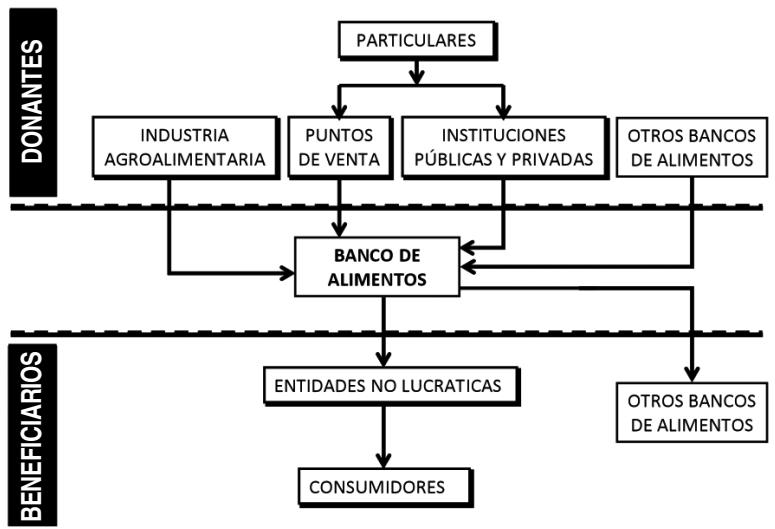

FUENTE: Elaboración propia.

Abordando el estudio de los bancos de alimentos desde el punto de vista de la cadena logística en la que se integran, cada banco depende de sus "proveedores" (las empresas y otras entidades donantes) que condicionan qué parte de la demanda de sus "clientes" (entidades receptoras que, a su vez, entregan los alimentos a las personas beneficiarias) puede satisfacerse. Entre las empresas que colaboran con los bancos se encuentran industrias productoras de alimentos, distribuidoras, grandes superficies, mayoristas, almacenistas, comerciantes, industrias de transporte, industrias de construcción, entidades financieras, empresas de publicidad y de comunicación (periódicos, radio, TV y medios electrónicos). A las anteriores deben añadirse instituciones públicas y diversas organizaciones nacionales e internacionales. Por su lado, las entidades receptoras son normalmente organizaciones no gubernamentales sin ánimo de lucro de diverso tipo que incluyen las cocinas económicas, los albergues de personas sin techo, las casas de acogida para mujeres maltratadas, las asociaciones de ayuda a inmigrantes y un largo etcétera, todas las cuales pueden agruparse en dos tipos (Schneider, 2013): de consumo (EC: cocinan los alimentos recibidos y los sirven dentro de sus instalaciones) y de reparto (ER: redistribuyen los alimentos sin procesarlos).

Esta investigación se enmarca dentro de un estudio más amplio sobre los distintos eslabones que integran la cadena logística de la que forman parte los bancos de alimentos españoles. Trabajos anteriores habían analizado cualitativamente el caso del Banco de Alimentos de Asturias (Coque et al., 2012) e investigado cuantitativamente el conjunto de bancos de alimentos españoles (González-Torre et al., 2013; González-Torre y Coque, 2015). El estudio aquí expuesto pretende indagar en las relaciones "aguas abajo" del Banco de Alimentos de Asturias, esto es, las que mantiene con sus dos tipos de entidades beneficiarias. Para ello, se ha asumido un enfoque metodológico híbrido cuantitativo- 
cualitativo (Aguinis et al., 2010), combinando encuestas dirigidas a toda la población de entidades (primera fase, de carácter exploratorio) con un seminario-taller participativo para devolución y contraste de resultados (discusión ulterior y explicación de una parte de esos resultados profundizando en los mismos).

\section{2.- Estudio cuantitativo de las entidades beneficiarias del Banco de Alimentos de Asturias}

\subsection{Metodología}

Se ha optado en esta parte de la investigación por un estudio cuantitativo debido a ser una metodología que permite hacer inferencia a la totalidad de la población a partir de una muestra con una seguridad y precisión definidas (Pita y Pértegas, 2002). Para ello se toma como base de partida una revisión bibliográfica previa.

En total, el Banco de Alimentos de Asturias tiene 125 entidades beneficiarias, de las cuales 57 son de consumo $(45,6 \%)$ y 68 de reparto $(54,6 \%)$.

De acuerdo con el banco, se usaron dos cuestionaros, idénticos para ambos tipos de organizaciones. El primero de ellos, pensado para entrevista, es de carácter general y alberga preguntas, entre otras, sobre los colectivos atendidos y las actividades llevadas a cabo para comprobar el grado de cumplimiento de cada entidad con los requisitos establecidos por el banco de alimentos para ser beneficiaria del mismo. El segundo cuestionario es de carácter voluntario y su fin es descubrir aspectos a mejorar por el banco mediante opiniones sobre la calidad y los tipos de alimentos entregados, la frecuencia de reparto y el equipo humano del banco.

\subsection{Elaboración de los cuestionarios}

Se discutieron con las trabajadoras remuneradas del banco de alimentos borradores de cuestionario con base en la revisión bibliográfica, modelo que fue revisado por el patronato de la entidad. A continuación un pre-test con dos organizaciones beneficiarias, una de reparto y otra de consumo, dio lugar a algunas modificaciones.

Cara al posterior análisis descriptivo, se pretendía que las preguntas fueran lo más cerradas posibles siendo de diferentes tipos: de respuesta dicotómica, única o múltiple. Se incluyeron asimismo algunas cuestiones abiertas y semiabiertas. 


\subsubsection{Cuestionario de datos generales de las entidades receptoras de alimentos}

El cuestionario de datos generales está dividido en los bloques que esquematiza la tabla 1.

El primer bloque (Datos de la entidad) recoge información relativa a cómo contactar con la entidad beneficiaria, la persona que realiza la encuesta y la forma jurídica de la propia organización. Respecto al tipo de entidad se han consultado diversas fuentes españolas e internacionales que documentan las categorías planteadas. Así, Schneider (2013) define a las entidades de consumo como aquellas que procesan los alimentos que reciben y los sirven dentro de sus instalaciones a las personas necesitadas, mientras que Feeding America (2011) habla de las entidades de reparto como las que proporcionan a los usuarios finales los alimentos para la posterior preparación y consumo doméstico. Por otro lado, Berner y O'Brien (2004) detallan que las entidades beneficiarias pueden ser puntos de reparto que distribuyen artículos comestibles gratis, o cocinas económicas las cuales dan comidas preparadas en el sitio. Montero Simó (2010) explica las clases y formas jurídicas que adoptan las entidades sin ánimo de lucro en Estados Unidos, así como la regulación de las mismas. Álvarez Vega (1999) explica cómo las entidades no lucrativas pueden adoptar cualquiera de las formas jurídicas previstas en el derecho español, siendo la fundación y asociación las más frecuentemente adoptadas. Además, las entidades basadas en la fe (FBOs- Faith Based Organizations) proporcionan una cantidad significativa de servicios sociales en Estados Unidos, paralelamente a organizaciones laicas -en la mayoría de las ciudades- 0 de forma mayoritaria -en comunidades más pequeñas- (Bielefeld y Cleveland, 2013). Ruiz Olabuénaga (2001) habla sobre el número y el tipo de organizaciones no lucrativas españolas y su distribución en las distintas áreas. El Anuario del Tercer Sector de Acción Social en España actualiza esos datos, especificando que esas entidades se dedican, en este orden, a sensibilización social, formación, información u orientación, gestión de servicios públicos, promoción del voluntariado, asesoramiento técnico, coordinación, asesoramiento jurídico, captación de recursos y otras actividades (Fundación Luis Vives, 2012).

El segundo bloque está destinado a los datos relacionados con la evolución de los beneficiarios finales y de los recursos humanos de que disponen las entidades sociales. Comenzando por los colectivos de intervención, el Equipo de Estudios Cáritas Española (2013) explica que sus principales perfiles sociodemográficos en España son las familias, los parados, los jóvenes en busca del primer empleo y las mujeres solas con cargas familiares. Laparra y Eransus (2008) presentan aproximaciones al análisis de la exclusión social realizadas para distintos colectivos: las personas sin hogar, las vinculadas al mundo penitenciario, los hogares monoparentales, las personas con enfermedad mental o con toxicomanías, la prostitución, la comunidad gitana y la inmigración. Ford et al. (2013) explican que los usuarios de CFPs (Community Food Programs) son personas sin empleo, que no tienen una educación secundaria o superior, y mayoritariamente mujeres. La Fundación Luis Vives (2009) sitúa entre los colectivos más afectados a los hogares con niños, las familias monoparentales, los jóvenes -especialmente los que viven solos-, las familias numerosas, los separados y divorciados, y las familias de inmigrantes. 


\section{Tabla 1. Encuesta de datos generales para entidades beneficiarias del Banco de Alimentos de Asturias}

\begin{tabular}{|c|c|c|c|}
\hline \multicolumn{2}{|c|}{ BLOQUES } & CONTENIDOS & FUENTES \\
\hline \multicolumn{2}{|c|}{$\begin{array}{l}\text { DATOS DE } \\
\text { LA ENTIDAD }\end{array}$} & Tipo de entidad & $\begin{array}{l}\text { Álvarez Vega (1999) } \\
\text { Berner y O’Brien (2004) } \\
\text { Bielefeld y Cleveland (2013) } \\
\text { Feeding America (2011) } \\
\text { Fundación Luis Vives (2012) } \\
\text { Montero Simó (2010) } \\
\text { Ruiz Olabuénaga (2001) } \\
\text { Schneider (2013) }\end{array}$ \\
\hline \multirow{6}{*}{ 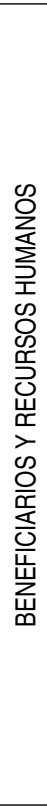 } & \multirow[b]{2}{*}{$\begin{array}{l}\text { Colectivos } \\
\text { beneficiarios }\end{array}$} & Colectivos de intervención & $\begin{array}{l}\text { Equipo de Estudios Cáritas Española (2013) } \\
\text { Ford et al. (2013) } \\
\text { Fundación Luis Vives (2009) } \\
\text { Laparra y Eransus (2008) }\end{array}$ \\
\hline & & Número de usuarios & $\begin{array}{l}\text { Berner y O'Brien (2004) } \\
\text { Equipo de Estudios Cáritas Española (2013) } \\
\text { Daponte y Bade (2006) } \\
\text { Davis y Tarasuk (1994) } \\
\text { Starkey (1994) } \\
\text { Starkey et al. (1999) } \\
\text { Tarasuk y Beaton (1999) }\end{array}$ \\
\hline & \multirow{4}{*}{$\begin{array}{l}\text { Recursos } \\
\text { humanos }\end{array}$} & Número de trabajadores & \multirow{2}{*}{$\begin{array}{l}\text { Consejería Empleo y Mujer Comunidad de Madrid (2009) } \\
\text { Jiménez Lara (1999) } \\
\text { Kapucu et al. (2011) } \\
\text { Lampkin y Boris (2002) }\end{array}$} \\
\hline & & Puestos de trabajo & \\
\hline & & Número de voluntarios & $\begin{array}{l}\text { INE (2010) } \\
\text { Kapucu et al. (2011) }\end{array}$ \\
\hline & & $\begin{array}{l}\text { Objetivos } \\
\text { Programas } \\
\text { Servicios ofertados }\end{array}$ & $\begin{array}{l}\text { Bielefeld y Cleveland (2013) } \\
\text { Equipo de Estudios Cáritas Española (2013) } \\
\text { Fundación Luis Vives (2009) } \\
\text { Vidal (2008) }\end{array}$ \\
\hline \multirow{4}{*}{\multicolumn{2}{|c|}{$\begin{array}{l}\text { RECOGIDA Y } \\
\text { MANIPULACIÓN } \\
\text { DE ALIMENTOS }\end{array}$}} & $\begin{array}{l}\text { Espacios relacionados directamente } \\
\text { con el reparto de alimentos }\end{array}$ & Cai et al. (2010) \\
\hline & & Vías de recepción de alimentos & $\begin{array}{l}\text { Tarasuk y Eakin (2003) } \\
\text { Teron y Tarasuk (1999) }\end{array}$ \\
\hline & & Local para almacenamiento & Solak et al. (2012) \\
\hline & & $\begin{array}{l}\text { Proceso de recogida, clasificación, } \\
\text { almacenamiento y reparto de alimentos } \\
\text { Personas que intervienen en ese proceso }\end{array}$ & $\begin{array}{l}\text { Cai et al. (2010) } \\
\text { Tarasuk y Eakin (2005) }\end{array}$ \\
\hline \multicolumn{2}{|c|}{ FINANCIACIÓN } & $\begin{array}{l}\text { Ingresos } \\
\text { Gastos }\end{array}$ & $\begin{array}{l}\text { Bielefeld y Cleveland (2013) } \\
\text { Lampkin y Sumariwalla (1999) }\end{array}$ \\
\hline
\end{tabular}

FUENTE: Elaboración propia. 
En 2005, de 24 a 27 millones de norteamericanos (alrededor de la duodécima parte de la población de Estados Unidos) recibió alimento de una entidad no lucrativa por lo menos una vez al año (Daponte y Bade, 2006). En España, el número de personas atendidas por los servicios sociales pasó de 370.251 en 2007 a 1.300 .914 en 2012 siendo el 26\% de ellas personas solas y el resto familias (Equipo de Estudios Cáritas Española, 2013). Por ello, el número de usuarios es una variable clave a estudiar. Según Starkey et al. (1999), los individuos y familias que necesitan asistencia alimentaria han ido creciendo en Canadá. El desempleo y subempleo fueron también explicaciones comunes para el aumento de clientes de este tipo de servicios, seguidos por la información boca a boca, el aumento de la población, la inmigración y las inundaciones (Tarasuk y Beaton, 1999). El número de clientes de asistencia de alimentación de emergencia aumenta en invierno y, durante todo el año, al final de cada mes (Berner y O'Brien, 2004). Ya antes de la crisis crecía la demanda de los bancos de alimentos y otras entidades benéficas en busca de asistencia alimentaria familiar y personal (Davis y Tarasuk, 1994; Starkey, 1994).

Lampkin y Boris (2002) señalan la importancia del tamaño del sector no lucrativo en Estados Unidos. Se sabe que hay 1,6 millones de entidades no lucrativas y que estas dan empleo a 11 millones de personas. Por ello, en el presente estudio se incluyen dos ítems al respecto: el número de trabajadores y los puestos de trabajo. Por su parte, Jiménez Lara (1999) explica que el sector no lucrativo español supera, en términos de empleo, a muchos sectores empresariales del país, incluidos transportes y comunicaciones, alimentación, bebidas y tabaco, metalurgia, textil, y las industrias químicas. Un estudio internacional del año 2003 impulsado por la Universidad Johns Hopkins en Baltimore (EEUU) explica que las organizaciones no lucrativas en España pasaron de 253.207 en 1995 a 362.654 en 2002, y que el crecimiento del empleo remunerado en ese mismo periodo fue del $45,7 \%$ pasando de 457.179 empleos equivalentes a jornada completa a 692.336 (Consejería de Empleo y Mujer de la Comunidad de Madrid, 2009).

Kapucu et al. (2011) analizan la relación entre el número de clientes atendidos y el número de trabajadores remunerados y voluntarios, además de las necesidades de formación de todos ellos; de aquí el interés por conocer el tamaño del voluntariado de base. El sector no lucrativo español canaliza un considerable volumen de esfuerzo voluntario en el que se implica un 17\% de la población adulta, esto es, 873.171 personas en 28.790 entidades de acción social (INE, 2010).

El aumento de las necesidades ha provocado el colapso de los servicios sociales públicos, lo que ha redundado en una mayor presión sobre las entidades privadas para atender a personas en situación de urgencia; las administraciones locales y autonómicas carecen de suficiente presupuesto o flexibilidad para adaptarse a nuevas situaciones planteadas por la crisis (Fundación Luis Vives, 2009). Las entidades no lucrativas deberían ser capaces de lidiar con el doble reto que se les plantea: por una parte, afrontar el impacto de la crisis en su funcionamiento y, por otra, dar respuesta a las necesidades sociales emergentes (Vidal, 2008). En el informe del Equipo de Estudios Cáritas Española (2013) figuran los servicios más demandados por los destinatarios finales: alimentación, ayudas para 
la vivienda, búsqueda de empleo, ropa y calzado, salud y farmacia, y formación (académica y/o social), además de otros como la escucha, el apoyo social o la mediación en situaciones conflictivas. Según Bielefeld y Cleveland (2013), las entidades basadas en la fe proporcionan una amplia variedad de servicios dirigidos a la rehabilitación de criminales y personas con toxicomanías. Por todo ello, tiene sentido incluir tres variables más de estudio: objetivos de la entidad, programas y servicios ofertados.

En el tercer bloque se recoge información acerca de los procesos de recogida y entrega de los alimentos, y los recursos físicos y humanos involucrados. Cai et al. (2010) exponen que las operaciones logísticas con artículos frescos como pescado, frutas o vegetales son un reto por ser muy perecederos. De ahí la importancia de tener los medios de transporte adecuados.

En Canadá, la mayoría de la comida que distribuyen los bancos de alimentos proviene de productores alimentarios, procesadores y minoristas o de campañas dirigidas al público. Las donaciones de algunas industrias son de calidad de mercado pero muchas otras donaciones son "excedentes" que no pueden ser vendidos al por menor. Los productos no perecederos mal etiquetados pero aptos para el consumo, los embalajes incorrectos, el error de estimación de cantidades de producción 0 los defectos de productos elaborados son algunas de las razones para donar productos (Tarasuk y Eakin, 2003).

Solak et al. (2012) presentan una variante de los problemas de localización y rutas (LRP, LocationRouting Problems) cuyo fin es minimizar los costes con la selección del emplazamiento para una serie de instalaciones y determinar las rutas óptimas de vehículos para recoger los alimentos. Esto refuerza el interés de conocer y estudiar la localización de las entidades beneficiarias de un banco de alimentos con respecto a los puntos de entrega de este.

En cuanto a la entrega, el caso de una cadena de suministros de productos frescos en el que el distribuidor aguas abajo es el responsable del transporte a larga distancia, estudiado por Cai et al. (2010), resulta muy similar al de las entidades beneficiarias del Banco de Alimentos de Asturias que son quienes deben trasladarse a recoger la mercancía. Los procesos de clasificación y almacenamiento empiezan cuando la comida llega a la entidad, los operarios la clasifican en categorías atendiendo a la distribución de la comida y si es almacenada o refrigerada para su uso posterior; manejar alimentos procesados no vendibles requiere trabajo extra (Tarasuk y Eakin, 2005).

El cuarto y último bloque se destina a las fuentes de financiación, que suelen ser mayoritariamente de carácter público. Estudios sobre la colaboración entre entidades no lucrativas basadas en la fe y el gobierno indican que dos tercios de aquellas obtienen financiación de este para extender sus servicios a más personas (Bielefeld y Cleveland, 2013). Lampkin y Sumariwalla (1999) analizaron variables de tipo financiero en más de 33.000 entidades no lucrativas. 


\subsubsection{Cuestionario de valoración sobre el Banco de Alimentos de Asturias}

La segunda encuesta contiene elementos comunes con la anterior, por lo que solamente se indican ahora nuevos aspectos como son la calidad, la cantidad de los alimentos y la frecuencia de reparto (tabla 2).

\section{Tabla 2. Cuestionario de evaluación de las entidades beneficiarias al Banco de Alimentos de Asturias}

\begin{tabular}{|l|l|l|}
\hline BLOQUES & CONTENIDOS & FUENTES \\
\hline \multirow{3}{*}{ ALIMENTOS } & Cantidad de alimentos & $\begin{array}{l}\text { Starkey et al. (1999) } \\
\text { Tarasuk y Eakin }(2003,2005)\end{array}$ \\
\cline { 2 - 3 } & Calidad de alimentos & $\begin{array}{l}\text { Handforth et al. (2012) } \\
\text { Tarasuk y Eakin (2003) }\end{array}$ \\
\hline PROCESO DE ENTREGA/ RECOGIDA & Frecuencia de reparto & Tarasuk y Eakin (2005) \\
\hline
\end{tabular}

FUENTE: Elaboración propia.

Según Starkey et al. (1999), las bolsas de comida de emergencia varían mucho en la cantidad de nutrientes que proporcionan. Handforth et al. (2012) explican que la mayor parte del personal de los bancos de alimentos se esfuerza en ofrecer más productos frescos a sus beneficiarios. Además, algunos bancos de alimentos han implementado sistemas de nutrición para evaluar la calidad de los productos con el fin de disminuir la distribución de productos bajos en nutrientes.

La cantidad de alimentos varía en función de la demanda y las limitaciones de provisiones, que pueden restringir la frecuencia, cantidad y variedad de comida que los clientes individuales reciban. Las peticiones de los clientes pidiendo asistencia adicional y quejas sobre los alimentos recibidos podrían interpretarse como una expresión de ingratitud, mientras que investigaciones previas indican repetidamente que las demandas de asistencia de bancos de alimentos exceden las provisiones disponibles. En particular, con relación a la frecuencia, la mayoría de los bancos de alimentos canadienses distribuyen la comida dos o tres veces por semana, operando típicamente durante dos a cuatro horas cada vez (Tarasuk y Eakin, 2005).

\subsection{Población y muestra}

La población objeto de este estudio son todas las entidades beneficiarias del Banco de Alimentos de Asturias (BAA).

La tabla 3 indica las tasas de respuesta y sus consiguientes errores muestrales para un nivel de confianza del $95 \%$. Ambas tasas de participación para la encuesta de datos generales y la de valoración son elevadas, superiores al $89 \%$, lo que hace que la muestra sea representativa de la pobla- 
ción estudiada, siendo aconsejable una tasa de respuesta del $85 \%$ al $90 \%$ para publicaciones en revistas de prestigio (Totten et al., 1999).

\section{Tabla 3. Ficha técnica de las encuestas}

\begin{tabular}{|c|c|c|c|}
\hline \multicolumn{2}{|c|}{ Población objetivo } & $\begin{array}{c}\text { Todas las entidades de consumo } \\
\text { beneficiarias del BAA }\end{array}$ & $\begin{array}{c}\text { Todas las entidades de reparto } \\
\text { beneficiarias del BAA }\end{array}$ \\
\hline \multicolumn{2}{|c|}{ Unidad de análisis } & Cada entidad de consumo & Cada entidad de reparto \\
\hline \multirow{2}{*}{\multicolumn{2}{|c|}{ Tamaño poblacional }} & 57 entidades de consumo & 68 entidades de reparto \\
\hline & & \multicolumn{2}{|c|}{ Las 125 entidades beneficiarias del Banco de Alimentos de Asturias } \\
\hline \multirow{2}{*}{$\begin{array}{l}\text { Tasa de } \\
\text { respuesta }\end{array}$} & $\begin{array}{c}\text { Encuesta de } \\
\text { datos generales }\end{array}$ & $\begin{array}{c}57 \text { entidades de consumo } \\
(100 \%)\end{array}$ & $\begin{array}{c}61 \text { entidades de reparto } \\
(89,7 \%)\end{array}$ \\
\hline & $\begin{array}{c}\text { Encuesta voluntaria } \\
\text { de valoración }\end{array}$ & $\begin{array}{l}42 \text { entidades de consumo } \\
(73,7 \%)\end{array}$ & $\begin{array}{c}57 \text { entidades de reparto } \\
(83,8 \%)\end{array}$ \\
\hline \multicolumn{2}{|c|}{ Nivel de confianza } & $95 \%$ & $95 \%$ \\
\hline \multirow{2}{*}{$\begin{array}{l}\text { Error } \\
\text { muestral }\end{array}$} & $\begin{array}{c}\text { Encuesta de } \\
\text { datos generales }\end{array}$ & $0 \%$ & $4,06 \%$ \\
\hline & $\begin{array}{l}\text { Encuesta voluntaria } \\
\text { de valoración }\end{array}$ & $7,8 \%$ & $5,3 \%$ \\
\hline \multicolumn{2}{|c|}{ Método de realización } & \multicolumn{2}{|c|}{ Entrevista personal, correo electrónico, correo ordinario y teléfono } \\
\hline \multicolumn{2}{|c|}{ Periodo de realización } & \multicolumn{2}{|c|}{ 07/02/2012 - 14/03/2014 } \\
\hline
\end{tabular}

FUENTE: Elaboración propia.

\subsection{Resultados cuantitativos}

\subsubsection{Datos generales de las entidades beneficiarias del Banco de Alimentos de Asturias}

La figura 2 muestra que la mayor parte de las EC entraron en contacto con el Banco de Alimentos de Asturias antes de la crisis, justo lo contrario que las ER, cuya expansión se produce a partir de 2005 y más intensamente desde 2010. Por tanto, es probable que las primeras estén más consolidadas, mientras que muchas del segundo tipo hayan sido creadas o se hayan desarrollado a causa de la crisis económica y estén sufriendo situaciones más precarias.

El total de personas beneficiarias en las EC es menor que en las ER (tanto en valores totales como medios), destacando entre las primeras la forma jurídica de asociación y entre las segundas las organizaciones religiosas. En ambas tipologías se realiza un menor número de trámites administrativos para organizarse sin ser necesario tener un sustrato patrimonial inicial. Tan sólo dos ER, una con 1.224 usuarios repartidos entre Oviedo y Gijón y la otra con 2.400 beneficiarios en la ciudad de Oviedo, absorben la mayor parte de datos de la forma legal fundación destacando la gran diferencia en el número medio de usuarios entre ambas organizaciones (tabla 4). 
La tabla 5 revela que la modalidad asociación cuenta con mayor volumen de voluntariado para ambos tipos de organizaciones beneficiarias. Las EC disponen de más personas voluntarias que las ER (tanto en valores totales como medios) aun siendo cierto que las ER apenas poseen trabajadores remunerados.

\section{Figura 2. Inicio de la relación entidad - Banco de Alimentos de Asturias según el tipo de organización beneficiaria}

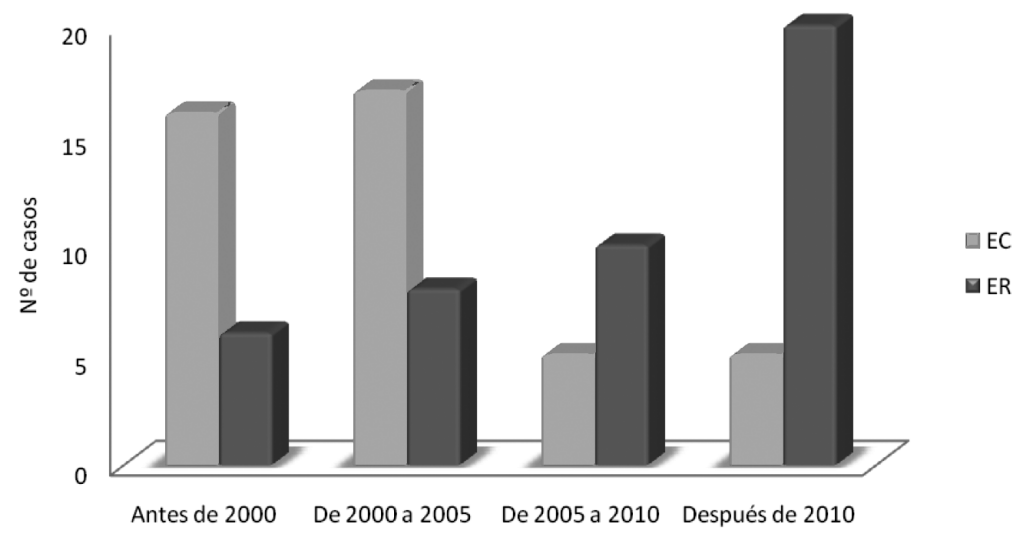

Tabla 4. Número de personas beneficiarias en función del tipo de entidad

\begin{tabular}{|l|cc|cc|cc|}
\hline TIPO ENTIDAD & \multicolumn{2}{|c|}{ TOTAL } & \multicolumn{2}{c|}{ MEDIA } & \multicolumn{2}{c|}{ DESVIACIÓN TíPICA } \\
\hline & EC & ER & EC & ER & EC & ER \\
\hline Asociación & 3.617 & 3.418 & 157,3 & 106,8 & 228,2 & 84,8 \\
Entidad religiosa & 1.733 & 4.391 & 72,2 & 168,9 & 67,5 & 191,4 \\
Fundación & 2.114 & 3.624 & 234,9 & $1.812,0$ & 343,0 & 831,6 \\
\hline TOTAL & 7.464 & 11.433 & 133,3 & 190,6 & 208,3 & 352,4 \\
\hline
\end{tabular}

FUENTE: Elaboración propia. 


\section{Tabla 5. Número de voluntarios según el tipo de entidad beneficiaria}

\begin{tabular}{|l|cc|cc|cc|}
\hline TIPO ENTIDAD & \multicolumn{2}{|c|}{ TOTAL } & \multicolumn{2}{c|}{ MEDIA } & \multicolumn{2}{c|}{ DESVIACIÓN TíPICA } \\
\hline & EC & ER & EC & ER & EC & ER \\
\hline Asociación & 471 & 304 & 21,1 & 10,9 & 25,8 & 11,2 \\
Entidad religiosa & 223 & 268 & 10,4 & 10,3 & 14,7 & 6,7 \\
Fundación & 280 & 76 & 31,1 & 38,0 & 46,6 & 17,0 \\
\hline TOTAL & 974 & 648 & 18,4 & 11,6 & 27,2 & 10,7 \\
\hline
\end{tabular}

FUENTE: Elaboración propia.

Tal y como se observa en la figura 3, los principales colectivos beneficiarios están formados por familias (más en ER), inmigrantes (más en ER), personas mayores (más en ER) y menores (más en EC). Cabe mencionar asimismo la atención de estas organizaciones hacia cualquier colectivo (más en ER) donde tiene en cuenta tan solo la necesidad de las personas, atendiendo a mujeres, niños u otros colectivos vulnerables o en riesgo de exclusión social.

\section{Figura 3. Tipos de colectivos beneficiarios en función del tipo de entidad}

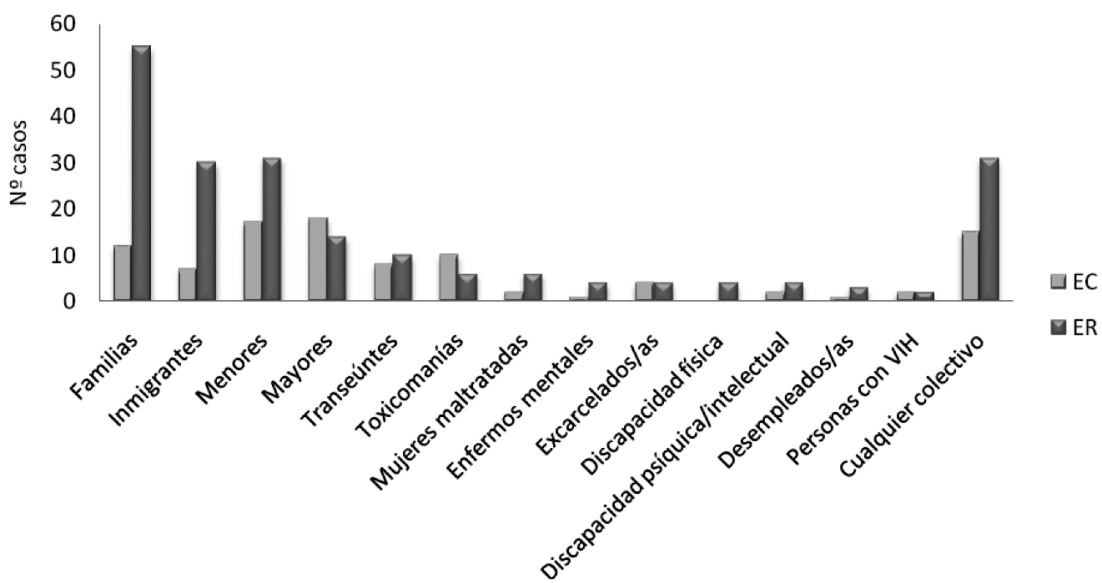

FUENTE: Elaboración propia.

Aparte de la alimentación en las EC y la entrega de alimentos en las ER, ambos tipos de entidades ofrecen, en diferente proporción, otros servicios de carácter social, especialmente alojamiento 
(más en las EC), educación y ocio (más en las ER), asesoría sobre aspectos legales y ayudas (más en las ER) y sensibilización (más en las ER) (figura 4).

Se observa en la figura 5 que aproximadamente la mitad de las entidades reciben alimentos del Programa de Excedentes de la Unión Europea y otros planes públicos que gestiona el Banco de Alimentos de Asturias. La práctica totalidad de las ER y tres cuartas partes de las EC son beneficiarias de la actividad propia del Banco de Alimentos de Asturias.

Otras fuentes de alimentos, minoritarias todas ellas respecto a la aportación que reciben del Banco de Alimentos de Asturias, son las donaciones privadas o la aportación de Cruz Roja (especialmente para EC en ambos casos, que se restringe al Programa de Excedentes de la Unión Europea, de carácter intermitente, al no contar dicha organización con una estructura permanente de gestión de alimentos), así como las recogidas propias (más en el caso de las ER) (figura 6).

Como es lógico dado que preparan para la ingesta los alimentos en sus propias instalaciones, y tal y como se muestra en la figura 7, casi todas las entidades de consumo cuentan con cocina, y la mayoría con despensa, almacén y comedor. Menos de la mitad de las entidades de reparto tienen esas instalaciones (ninguna de ellas dispone de comedor, lo cual es nuevamente coherente con su naturaleza).

\section{Figura 4. Tipos de actividades desarrolladas dentro de cada entidad beneficiaria}

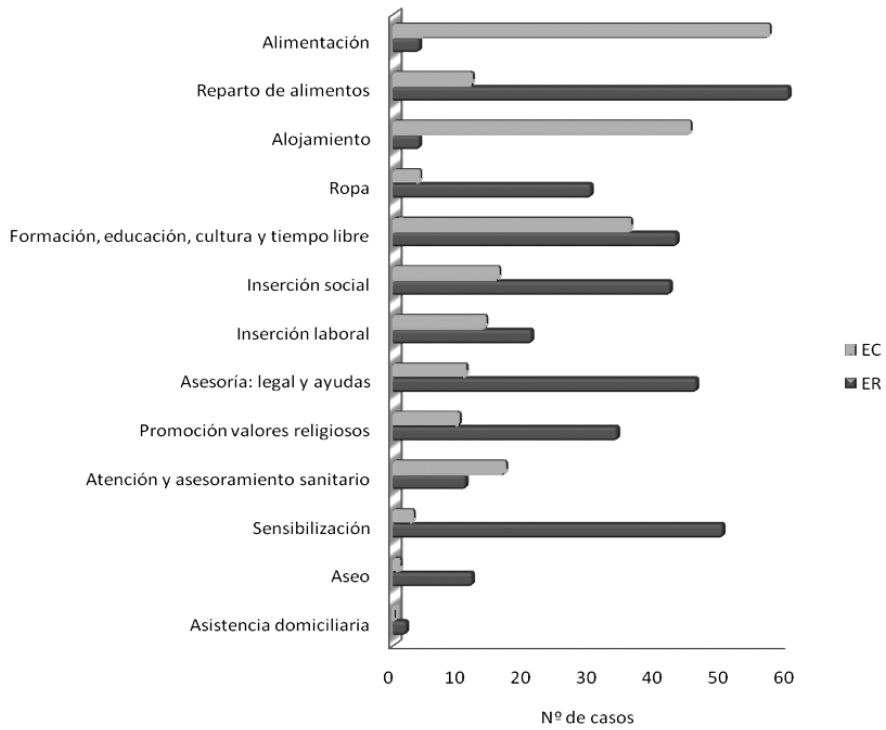

FUENTE: Elaboración propia. 
Figura 5. Porcentaje de entidades beneficiarias que se proveen del Banco de Alimentos de Asturias

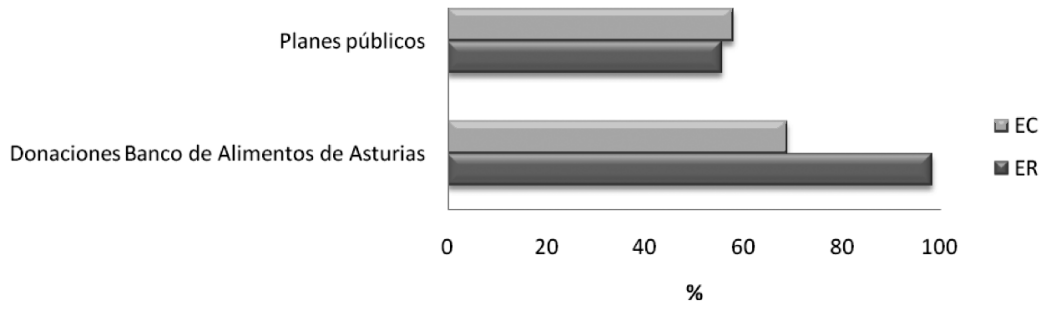

FUENTE: Elaboración propia.

\section{Figura 6. Fuentes diferentes al Banco de Alimentos de Asturias}

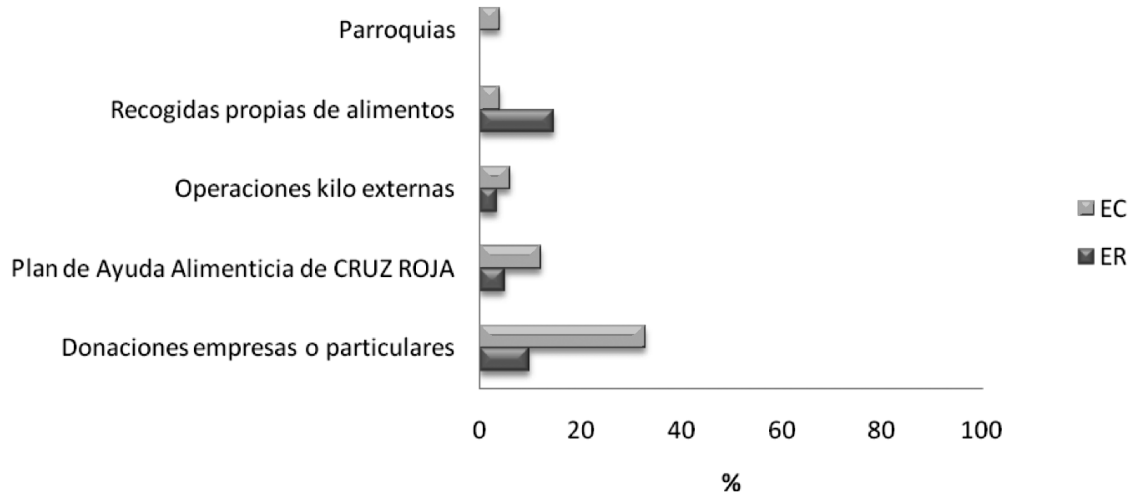

FUENTE: Elaboración propia. 


\section{Figura 7. Tipo de instalaciones de preparación y conservación de alimentos}

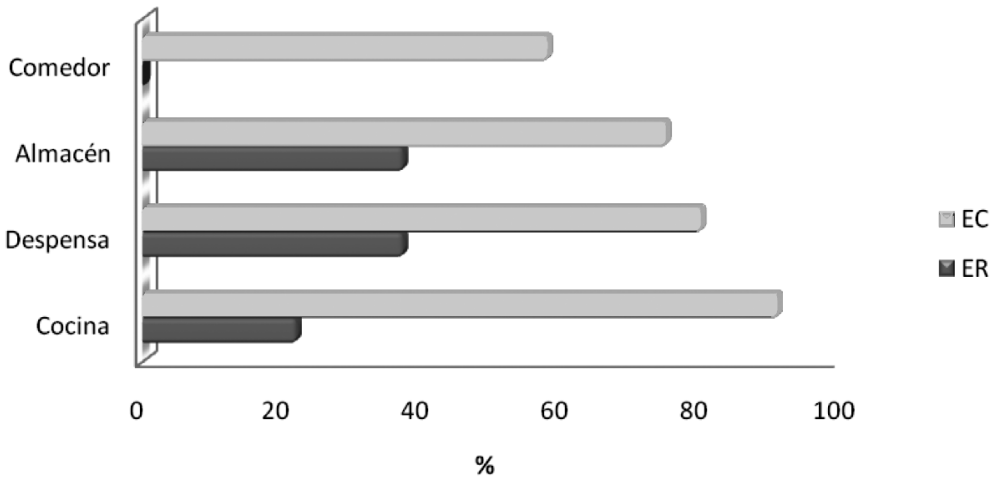

FUENTE: Elaboración propia.

\subsubsection{Opiniones sobre el Banco de Alimentos de Asturias por parte de sus entidades bene- ficiarias}

La satisfacción respecto a la calidad de alimentos recibidos del Banco de Alimentos de Asturias es en general alta, aunque alrededor de la mitad de las ER declara recibir menos productos de los demandados (figura 8).

Las EC reciben alimentos con mayor frecuencia que las ER (figura 9), manifestando las primeras estar más satisfechas al respecto que las segundas (figura 10).

En cuanto a la composición de lo recibido, parece que determinados grupos de alimentos, como las farináceas, las legumbres, las galletas, los postres o los refrescos, llegan de forma suficiente (figura 11) con relación a lo demandado, mientras que no sucedería lo mismo con otros (productos frescos, alimentos infantiles, aceite, azúcar), tal y como muestra la figura 12. Cabe destacar que las EC perciben en mayor cantidad que las ER productos frescos como lácteos, huevos, pescado, frutas y verduras siendo mayor la entrega de aceite, azúcar, galletas y productos infantiles a las ER.

Las EC, que contarían con fuentes financieras propias, donaciones y subvenciones públicas, son menos dependientes del Banco de Alimentos de Asturias que las ER, pues una proporción relevante de estas últimas obtiene todos o una mayoría de los alimentos en el banco de alimentos (figura 13). Tanto las EC como las ER parecen estar satisfechas con el sistema de entrega de los productos (figura 14). 
Figura 8. Opiniones sobre cantidad y calidad de los alimentos recibidos

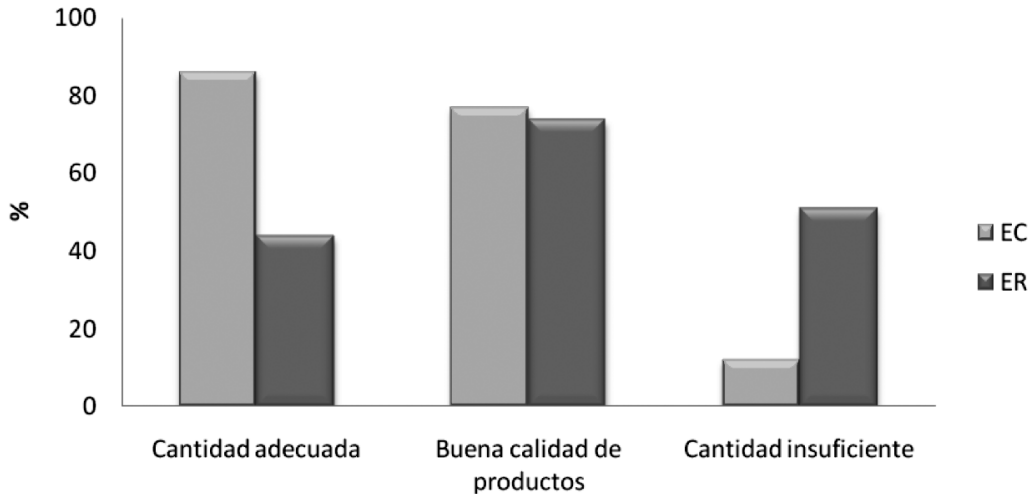

FUENTE: Elaboración propia.

Figura 9. Frecuencia con la que las entidades reciben alimentos
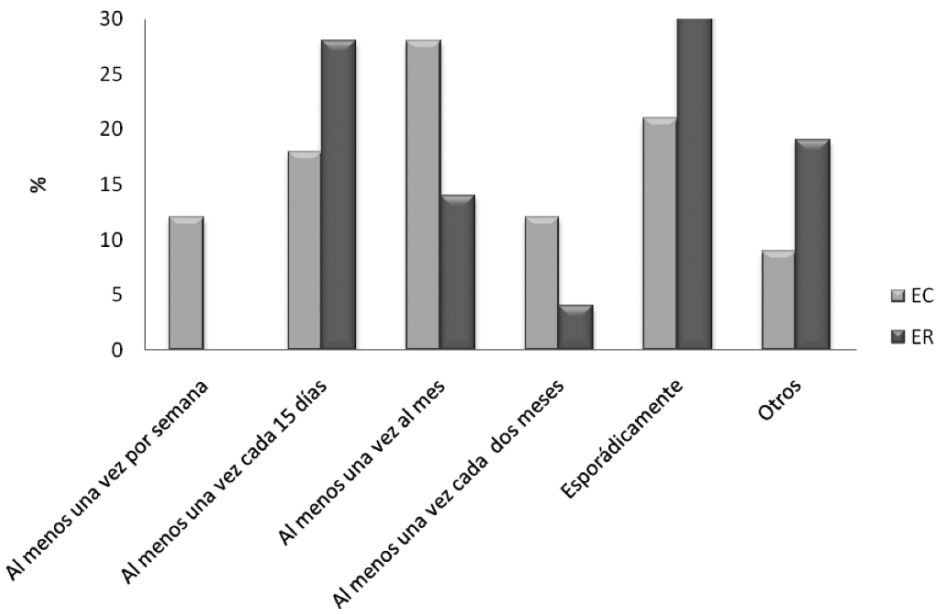

FUENTE: Elaboración propia. 
Figura 10. Adecuación de la frecuencia con la que se recibe los alimentos

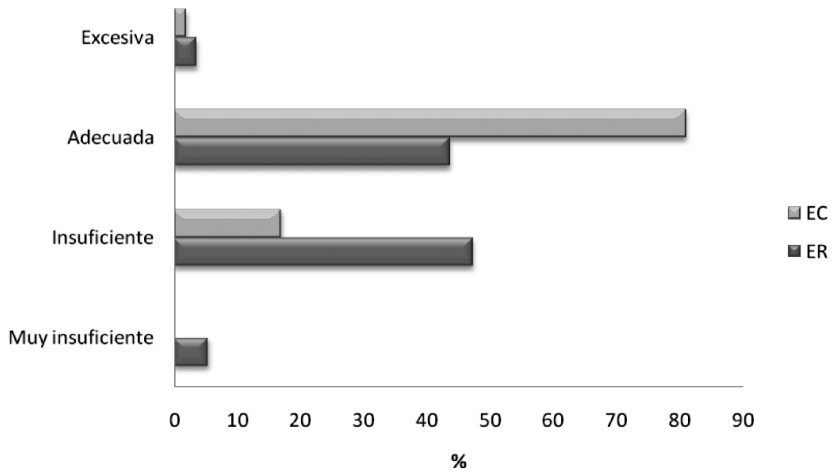

FUENTE: Elaboración propia.

Figura 11. Alimentos que reciben las entidades beneficiarias del Banco de Alimentos de Asturias

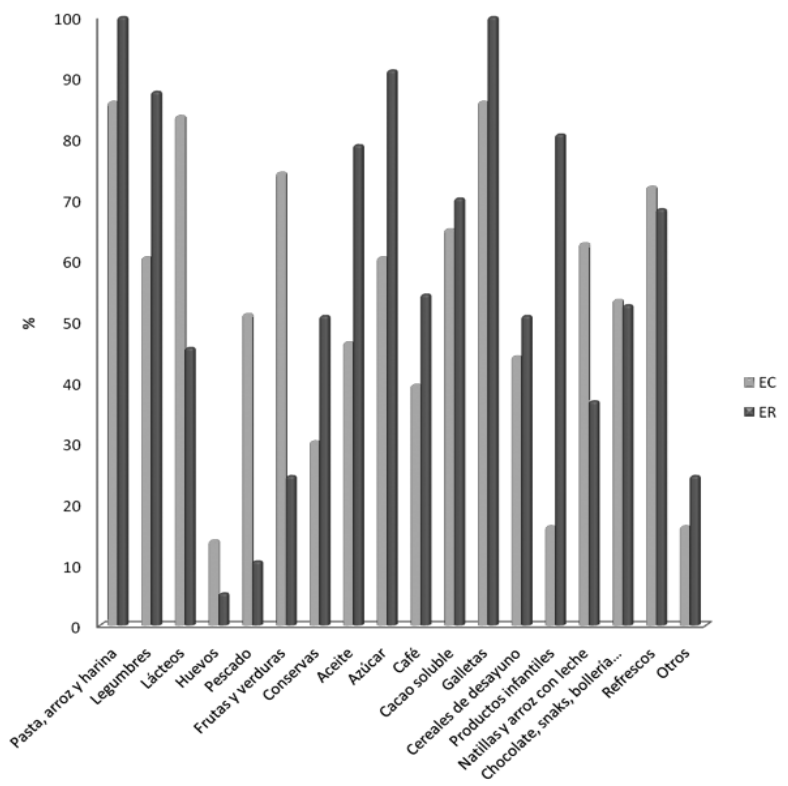

FUENTE: Elaboración propia. 
Figura 12. Alimentos que les gustaría recibir en mayor frecuencia/cantidad a las entidades beneficiarias del Banco de Alimentos de Asturias

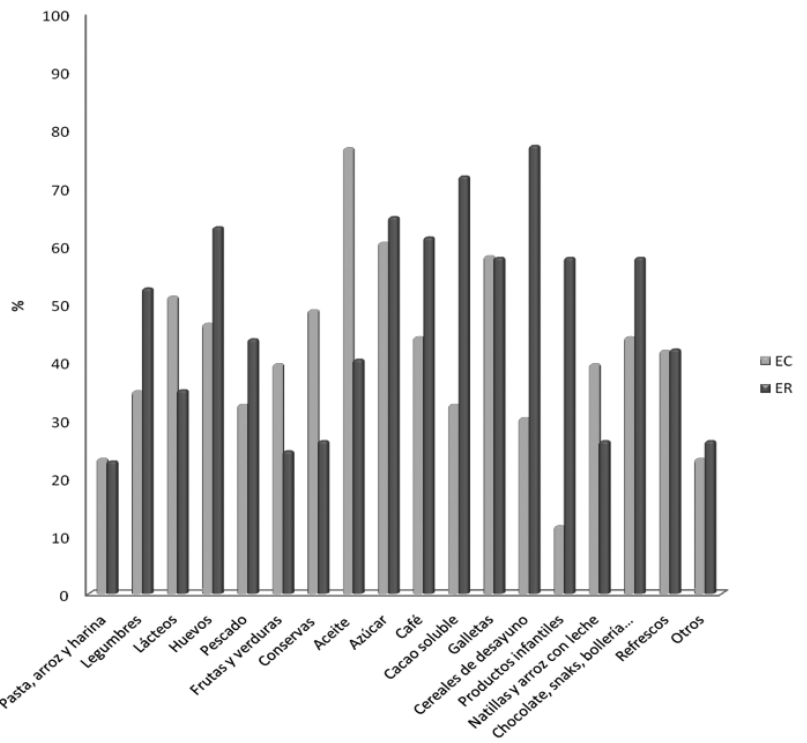

FUENTE: Elaboración propia.

Figura 13. Necesidades cubiertas por el Banco de Alimentos de Asturias en sus entidades beneficiarias

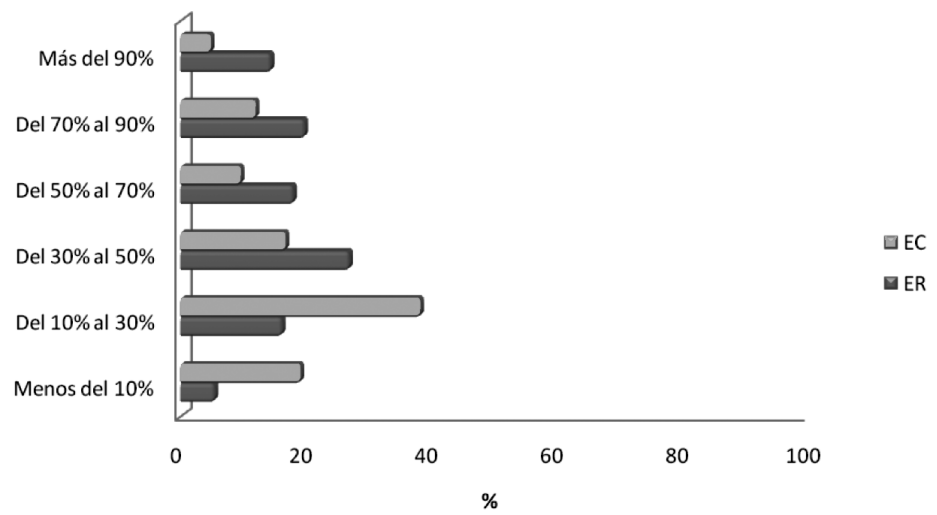

FUENTE: Elaboración propia. 


\section{Figura 14. Valoración sobre la organización en la recogida/entrega de alimentos}

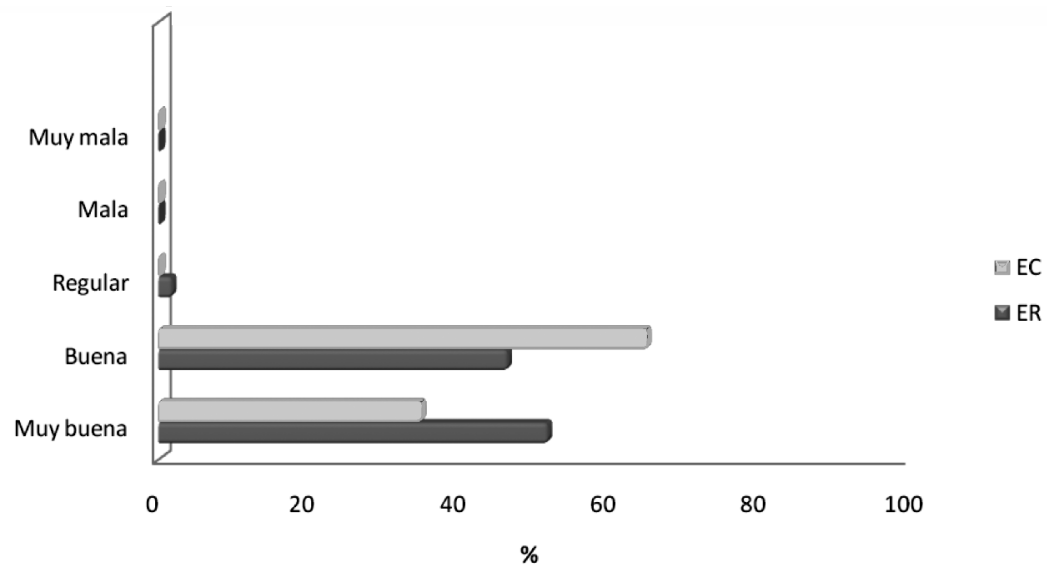

FUENTE: Elaboración propia.

\subsection{Discusión sobre los resultados del estudio cuantitativo}

Una vez expuesta la información obtenida, se procede a interpretarla para analizar la situación de las entidades beneficiarias del Banco de Alimentos de Asturias en el contexto de la crisis económica así como los aspectos mejorables encontrados.

La mayoría de las EC beneficiarias del Banco de Alimentos de Asturias entraron en contacto con este antes del año 2005, previamente a la crisis económica, todo lo contrario que las ER, cuyo primer contacto con el banco fue a raíz de ella; de hecho, tres cuartas partes de las mismas se formaron a partir del año 2005. Las segundas son, pues, entidades relativamente jóvenes, que trabajan al día resolviendo lo más urgente, con apenas medios económicos y materiales para llevar a cabo sus programas. Las EC serían entidades más consolidas y con mayores medios.

Pese a parecer más precarias, las ER atienden a unas 4.000 personas más que las $\mathrm{EC}$, demanda que se ha visto multiplicada y que se prevé que continúe creciendo tal y como afirma el banco de alimentos al explicar que en 2012 atendió a 17.000 personas en Asturias y que 2013 se cerró con 25.000 (La Nueva España, 2013).

La acción voluntaria en estas entidades es vital para su supervivencia. Se precisan personas sensibilizadas con los aspectos sociales, que además se comprometan asumiendo de forma responsa- 
ble su ofrecimiento de tiempo libre solidario, para poner sus capacidades y experiencias en beneficio de los demás, siempre de forma organizada y coordinada con otros voluntarios y profesionales (Junta de Castilla y León, 2014). Este es un reto conseguido por ambos tipos de organizaciones, si bien, las EC absorben más voluntarios, con cerca de 1.000 personas en total, frente a los casi 650 voluntarios con que cuentan las ER.

Por lo que respecta al tipo de colectivo beneficiario, las ER se centran en familias, inmigrantes y menores así como en cualquier colectivo, siendo este último el fin primordial de atención de las EC, que estarían menos especializadas. Esto confirma que muchas ER han nacido con y por la crisis; los perfiles más castigados y el fin principal de atención de estas entidades concuerdan con los datos expresados por El País (2014), que explica que el perfil de usuario ha cambiado. Ahora, el $57 \%$ son españoles y el resto inmigrantes, cuando pocos años atrás la proporción era inversa. Además de sus respectivos objetivos centrales (alimentación para las EC y entrega de alimentos para las ER), las EC dedican esfuerzos importantes al alojamiento y a formación y a ocio, mientras que las ER añaden sensibilización y asesoría, lo que concuerda con el desequilibrio de recursos entre unas y otras.

Las ER son más dependientes del Banco de Alimentos de Asturias al contar con menores espacios físicos relacionados directamente con la alimentación y con menos donaciones particulares o de empresas a pesar de poseer más recogidas propias de alimentos. De ahí que, aunque ambos tipos de entidades declaran encontrarse en general contentas con los servicios ofrecidos por el banco, existe cierta insatisfacción en las ER respecto a la cantidad percibida y la frecuencia de entrega, insuficientes con relación al aumento del número de usuarios y los escasos recursos de estas organizaciones.

Parece que ciertos productos, como las farináceas y las legumbres, cubren las necesidades de los usuarios en ambos tipos de organizaciones, aunque las $\mathrm{EC}$ reciben más productos frescos como huevos, pescado, frutas y verduras y las ER más aceite, azúcar, galletas y productos infantiles. Las EC demandan más aceite y conservas, mientras que las ER desearían recibir en mayor cantidad cereales y cacao soluble. El Banco de Alimentos de Asturias se encuentra satisfecho por haber ampliado la variedad de productos entregados a las familias, consiguiendo que ingieran alimentos necesarios para una dieta equilibrada cuando antes los lotes se limitaban a poco más que arroz, leche, galletas y pasta, claramente insuficientes para una alimentación saludable (Banco de Alimentos de Asturias, 2014).

La información resumida hasta aquí fue objeto de análisis cualitativo mediante el taller al que se refiere el epígrafe siguiente. 


\section{3.- Taller para devolución, profundización y contraste de los resultados del estudio cuantitativo}

\subsection{Metodología}

La hasta ahora última etapa del trabajo tenía como fin indagar en los porqués de algunos de los resultados expuestos hasta aquí. Para ello, se convocó una reunión de responsables de EC y ER elegidas por su representatividad (diferentes tamaños, formas jurídicas, localizaciones y colectivos destinatarios), del Banco de Alimentos de Asturias y del propio equipo de investigación de la Universidad de Oviedo. Finalmente, a la sesión, que tuvo lugar el 12 de diciembre de 2013 en dependencias del campus universitario de Gijón, acudieron quince personas: cinco representantes de entidades de consumo (denominadas seguidamente como EC1, EC2, EC3, EC4 y EC5), cuatro de reparto (ER1, ER2, ER3 y ER4), dos miembros del patronato del Banco de Alimentos de Asturias (BAA) y cuatro investigadores universitarios (UO).

La actividad fue concebida desde una óptica de investigación-acción participativa bajo la moderación del equipo de la universidad (tabla 6). Este enfoque metodológico parte del compromiso social directo del mundo académico, del investigador frente al investigado, cuyos respectivos papeles tradicionales de sujeto y objeto de estudio se difuminan e intercambian al construir la verdad conjuntamente (Díez, 2013). A lo largo de este tipo de procesos, los agentes externos (en este caso, los investigadores universitarios) aportan apoyo a la comunidad (en este caso, el BAA con sus EC y ER) en la formulación y jerarquización de sus problemas, formándose conjuntamente unos y otros. El análisis y aplicación de resultados, que incluye la propuesta de soluciones, evita la distancia tradicional entre el modelo teórico y la realidad donde operan beneficiarios pasivos.

\section{Tabla 6. Programa del taller participativo}

\begin{tabular}{|lll|}
\hline $\begin{array}{l}\text { Hora de } \\
\text { comienzo }\end{array}$ & Fase & Protagonistas \\
\hline $16 \mathrm{~h} 30$ & Presentación del acto y de las personas asistentes & Todas las personas participantes \\
$16 \mathrm{~h} 45$ & Resumen de los resultados del proyecto & UO \\
$17 \mathrm{~h} 00$ & Discusión & EC1...EC5; ER1...ER4, BAA \\
$18 \mathrm{~h} 00$ & Propuesta de futuros desarrollos del proyecto & Todas las personas participantes \\
$18 \mathrm{~h} 30$ & Clausura del acto & \\
\hline
\end{tabular}




\subsection{Discusión sobre los resultados de las encuestas}

Como refleja la tabla 6, tras la exposición de los datos anteriores por el grupo de investigación universitario (esencialmente, la información que recoge el epígrafe 2 del presente artículo, que sería más tarde completada y corregida tras conseguir más encuestas después del taller), se procedió a discutir los mismos con base en las preguntas que siguen.

\subsection{1. ¿Hasta qué punto las entidades presentes se sienten identificadas con los resultados mostrados?}

Tanto las ER como las EC se ven en general reflejadas en los datos medios que se presentaron previamente.

Para EC4 las cifras de los voluntarios son las más chocantes, indicando que las EC y las ER son distintas y por tanto sus necesidades también difieren. Del mismo modo, no todos los voluntarios se destinan a tareas vinculadas con los alimentos en las EC, como si puede pasar con las ER. Estas diferencias entre las propias ER y más de estas con las EC también son señaladas por los representantes de ER4 y EC2. Este último también indica que las EC están financiadas por proyectos y lo que reciben del BAA es una ayuda.

La representante de EC4 señala asimismo que las cifras de beneficiarios no se deberían sumar, puesto que puede haber duplicidades dado que un mismo usuario puede ser atendido en varias entidades diferentes. En su caso concreto atienden a las mismas personas en las cuatro comidas del día.

ER4, por su parte, muestra alguna discrepancia con el colectivo beneficiario, pues atienden a cantidades elevadas de inmigrantes y de personas pertenecientes al colectivo gitano que no se ven reflejadas en los datos medios.

\subsection{2. ¿Cuáles son los criterios del Banco de Alimentos de Asturias para asignar alimentos? ¿Son estos criterios adecuados?}

En general, todas las entidades conocen dos de los criterios fundamentales de asignación: el número de usuarios atendidos por cada entidad y las preferencias de la misma (tipo de alimentos que necesitan en cada caso). Sólo algunas organizaciones conocen la posibilidad de demandar directamente los alimentos que necesitan en cada momento al banco. EC3 es la única entidad presente que señala la capacidad de almacenaje como criterio de asignación.

Por su parte el BAA destaca como otro criterio la capacidad de los medios de transporte disponibles en cada caso. Reconocen que desde hace un año y medio los criterios han cambiado y que se debe distinguir entre los criterios para ser entidad beneficiaria y los de reparto de alimentos. En cuanto 
a los primeros, el volumen de nuevas solicitudes se ha disparado entre un 30 o un 40 por ciento a causa de la actual crisis económica. En este sentido, para que una entidad sea beneficiaria del banco debe estar legalmente constituida y bajo la vigilancia por parte del banco para que el reparto se realice de una forma organizada y sistemática.

Existe una diferencia en los criterios de asignación para los dos tipos de entidades existentes. La frecuencia en la entrega a las ER ha aumentado debido a la prioridad que se les da a este tipo de entidades con el fin de atender a las familias. Son las EC quienes mejor gestionan el producto perecedero por su mayor capacidad y por disponer de medios de almacenaje. En este aspecto existe una discrepancia con el BAA por parte de las ER presentes, quienes afirman ser capaces de entregar en el día productos perecederos a sus colectivos beneficiarios.

Al BAA le supone un sobreesfuerzo el trabajo con productos perecederos al comprometer a las EC a recibir gran cantidad de estos sin poseer estas, en ciertos momentos, capacidad de almacenaje o los medios de transporte necesarios. El objetivo ideal del banco es poder ser, en un futuro, el propio almacén de las entidades. Las EC asumen cualquier tipo de alimentos mientras que hay que dejar la variedad a las ER para que distribuyan lo que realmente precisan sus usuarios. EC1 señala que sería interesante conocer con días de antelación qué van a recibir para poder asumir las cantidades de alimentos. Parece que el propio funcionamiento del BAA y la incertidumbre en cuanto a la recepción de sus donantes hacen inviable este punto.

\subsection{3. ¿Es adecuado el procedimiento de entrega y recogida, así como la cantidad y la varie- dad de productos recibidos?}

EC2 considera que la adecuación del procedimiento depende del producto de que disponga el banco.

EC4 muestra la importancia de los puntos de recogida. Para ir al BAA debe destinar y pagar a una persona no voluntaria y el correspondiente medio de transporte. Una alternativa sería el aprovechamiento compartido de los viajes con otras entidades. En cuanto a los productos perecederos son limitados tanto en variedad como en cantidad y en su caso es importante contar con alimentos de primera necesidad para sus usuarios.

ER4, por su parte, recalca la mejora de la ubicación de la sede del BAA, frente a otra anterior. A su entidad le supone un problema guardar hasta la próxima entrega las "cajas verdes" en las que reparte el BAA por limitación de espacio. Los productos más demandados por ER4 son la leche y el aceite e insiste en disminuir la cantidad de pasta ya que tienen suficiente almacenado procedente de otras entregas. El procedimiento de entrega que siguen es repartir en función de lo que disponen. 
EC1 apunta una sugerencia para los donantes, puesto que cree que las entidades receptoras no deberían recibir "cualquier cosa". En ocasiones, frutas u otros productos perecederos llegan en condiciones no aptas para el consumo. Parece que ciertas entidades beneficiarias se limitan a tirar alimentos que deberían haber sido desechados previamente.

El BAA expone que este año el Programa de Excedentes de la UE ha comprado productos como aceite y que otros como la harina, que hasta ahora se servía en abundancia, van a escasear ya que estos van a desaparecer de la citada ayuda en el año 2015. En general, sería interesante conocer el consumo anual de las entidades beneficiarias, sobre todo en las EC, que cuentan con usuarios más fijos. Al respecto, EC2 sugiere poner en conocimiento del banco sus excedentes y no solo lo que consumen.

EC1 considera que otra dificultad es el no acondicionamiento de las furgonetas para transportar los productos alimenticios, lo que supone multas. El BAA informa de que ha gestionado con las autoridades la solución de este problema.

Retomando el tema de los alimentos, esta misma entidad sugiere que las EC dispongan de ciertas pautas para la ingesta o consumo, especialmente respecto a los productos perecederos como los yogures, que tienen fecha de consumo preferente pero que parece se podrían consumir con posterioridad a dicha fecha sin problemas de salubridad. EC3 sugiere que las ER tengan unas directrices de cajas básicas para entregar los alimentos a una familia de tamaño medio durante un determinado periodo de tiempo. El BAA responde que tiene una caja básica diseñada por un nutricionista y el problema es que los usuarios no saben muchas veces cómo preparar posteriormente los alimentos de manera adecuada o lo hacen inadecuadamente. EC3 insiste en hacer hincapié en este aspecto proponiendo el uso de vales como hace su propia entidad.

La UO pregunta si se tienen en cuenta los criterios culturales que puedan existir a la hora del reparto y que en algunos casos condicionarían el rechazo 0 aceptación de determinados productos. El BAA afirma que son tenidos en cuenta cuando se lo notifican las entidades beneficiarias.

\subsection{4. ¿Qué propuestas de mejora se pueden sugerir al Banco de Alimentos de Asturias?}

ER4 aporta la idea de reducir el tamaño de las cajas de entrega. No es adecuado que una sola persona maneje cajas de unos treinta kilos. El BAA responde que ya se va a empezar a aplicar una nueva normativa por la que las cajas no podrán superar los diez kilos de peso.

EC3 sugiere que las entidades se coordinen entre ellas para evitar duplicidades. ER1 señala que esto será difícil poder llevarlo a cabo debido a la ley de protección de datos, lo que le impide ceder

información de sus usuarios. Se discute si toda la información es tan sensible como la referente a aspectos de salud, y si no sería posible unificar unos pocos datos básicos que se requerirían a las personas beneficiarias de todas las entidades tras obtener su autorización. 
EC2, por su parte, indica la posibilidad de contar con un medio de transporte común desde el BAA, es decir, un recurso común de la red.

\subsection{5. ¿Futuros desarrollos del proyecto?}

Los miembros de UO exponen la siguiente propuesta de líneas de trabajo para 2014:

- Comparar exhaustivamente ambos tipos de entidades beneficiaras (vía comenzada ya en el presente taller), añadiendo al estudio entrevistas semiestructuradas a una muestra de EC y ER.

- Profundizar en los aspectos de intervención social de los que la provisión de alimentos sería solo una parte.

- Iniciar el estudio de las entidades donantes del BAA (el "aguas arriba" de la cadena logística del BAA).

El resto de participantes encuentran tales líneas suficientemente amplias como para recoger todo lo interesante a realizar el próximo año. No obstante, si se mantuviera el contacto, podrían ir surgiendo ideas más concretas como las que se recogen en los párrafos siguientes.

ER4 propone realizar una encuesta a los usuarios de las entidades beneficiarias, estudiando la cadena aún más "aguas abajo". En este sentido, ER3 insiste en que es una buena idea para conocer mejor las necesidades de cada colectivo en concreto. Otras personas comentan que esta idea puede aplicarse a la relación entre los alimentos y las diferentes culturas de los colectivos beneficiarios.

EC4 señala la necesidad de llevar a cabo una valoración económica de lo que entrega en cada caso el BAA. La entidad beneficiaria hace un apunte contable de entrada y salida, mientras que el banco se limita a recibir el albarán y emitir el certificado de valor fiscal. Los albaranes del banco son muy generalistas o utilizan referencias difíciles de interpretar para el receptor, lo que obstaculiza el recuento a la hora de la recogida. El BAA maneja la cifra estándar de 2,79 euros/kilo para valorar los productos, dato que ha cambiado recientemente tras ser consensuada por la Federación Europea de Bancos de Alimentos y en la que, además del coste económico de los propios alimentos, se incluye el trabajo del voluntariado.

\subsubsection{Evaluación del taller}

La coordinación y moderación a cargo del equipo universitario cierra la sesión manifestando que es la primera vez que se ha realizado un taller de este tipo y que se espera repetir jornadas similares tras el buen resultado obtenido. La mayoría del resto de participantes asienten. La próxima jornada podría tener lugar dentro de aproximadamente un año, aunque este plazo queda también sujeto a ser discutido y, en su caso, modificado según cómo transcurra el trabajo de investigación durante 2014. Antes de finalizar, se sugiere que las entidades aporten algunas consideraciones adicionales así como comentarios sobre el método aplicado en el taller. 


\subsection{Consideraciones finales sobre el taller}

Las personas participantes se sintieron identificadas en general con los datos promedio presentados como resultado del estudio, salvo casos puntuales muy concretos. No debe olvidarse que las EC y las ER beneficiarias del Banco de Alimentos de Asturias son muy heterogéneas, tanto entre sí como dentro de cada uno de ambos tipos. Por tanto, parece interesante seguir profundizando en estudios de detalle que evitarían la pérdida de información que puede darse en estudios cuantitativos, lo que facilitaría acercarse a sus realidades y mejorar el servicio que reciben. Solo generaron discrepancias de conjunto dos aspectos. Por un lado, algún error en los datos cuantitativos mostrados, donde aparecían intercambiadas las EC con las ER, que ya han sido subsanadas en el presente texto. Por otro, respecto al voluntariado, entendiendo que las cifras generales sobre personal disponible no son comparables entre EC y ER, pues en las segundas el voluntariado se dedicaría especialmente a proveer alimentos mientras que en las primeras estas personas se hallan repartidas en muchas más actividades; el equipo de investigación se replanteará este aspecto.

El taller fue valorado positivamente por las personas asistentes, en coherencia con el ambiente participativo y constructivo que reinó durante toda la sesión. Existe interés en mantener el contacto, aportar datos y volver a reunirse cuando se considere necesario, incorporando, en su caso, a otros agentes de la cadena logística del Banco de Alimentos de Asturias. Varias personas participantes pidieron que en un futuro taller se facilitara previamente la documentación con los datos sobre los que fuera a discutirse, medida que ya ha sido aplicada en un taller celebrado en 2014.

\section{4.- Conclusiones}

El estudio cuantitativo desarrollado revela que las entidades de reparto beneficiarias del Banco de Alimentos de Asturias son en su mayoría organizaciones jóvenes, fundadas con la crisis para ayudar a las personas más castigadas por esta, sin apenas recursos económicos ni materiales y muy dependientes de la ayuda recibida del banco, mientras que las entidades de consumo son generalmente más antiguas que, si bien soportan también dificultades en el contexto actual, se encuentran más consolidadas, mejor organizadas y con mayores recursos que les permiten cierta independencia del banco.

Las relaciones de este banco de alimentos con sus entidades beneficiarias (que, igual que él, son esencialmente gestionadas por voluntariado) parecen eficientes en cuanto al proceso de recogida y la planificación en conjunto de las actividades, aunque se detectan problemas de calidad en algunos productos y de sincronía entre demanda y oferta. Esto no resulta sorprendente cuando se observa el carác- 
ter perecedero de una parte de los alimentos que reciben y las largas distancias que tienen que recorrer para recogerlos, así como la habitual carencia de vehículos refrigerados. Factores clave de lo antedicho son que las entidades de consumo y de reparto son muy heterogéneas, tanto entre sí como dentro de cada uno de ambos tipos, y que los ciclos de aprovisionamiento del banco no se rigen por su demanda si no por la oferta de las empresas y otras organizaciones donantes.

En suma, se registra un alto grado de satisfacción con la ayuda prestada, si bien el taller participativo realizado ha permitido la propuesta de varias vías de mejora que incluyen tanto medidas prácticas a implantar de forma más o menos inmediata como sugerencias de desarrollos futuros de la presente línea de investigación:

- Controlar mejor el estado de los productos que entregan los donantes, especialmente los alimentos perecederos, mediante un incremento de la selección en origen.

- Reconsiderar la capacidad de las entidades de reparto para recibir productos frescos muy perecederos, que en este aspecto resultan comparativamente perjudicadas respecto a las entidades de consumo en la actualidad.

- Establecer una bolsa básica común que facilite la coordinación y la redistribución de productos entre entidades.

- Recoger información más real de lo que necesita cada entidad beneficiaria, lo que incluiría medidas como un sistema central de datos permanentemente actualizado vía web o una sistematización unificada de las bases de datos de los colectivos destinatarios. Esto permitiría conocer mejor las necesidades de estas personas, así como atajar duplicidades y picaresca. Asimismo, el incremento de la información mutua entre el banco y sus entidades beneficiarias facilitaría que aquel realizara sus entregas cuando estas estuvieran en las mejores condiciones de recibirlas.

- Profundizar en el conocimiento sobre las relaciones del Banco de Alimentos de Asturias con sus proveedores.

\section{Bibliografía}

AGUINIS, H., WERNER, S., ABBOTT, J., ANGERT, C., PARK, J. \& KOHLHAUSEN, D. (2010): "Customer-centric science. Reporting significant results with rigor, relevance, and practical impact in mind", Organizational Research Methods, 13, 515-539.

ÁLVAREZ VEGA, M. (1999): "Las empresas de inserción social como nueva forma de organización empresarial. Especial referencia a su régimen jurídico", CIRIEC-España, Revista de Economía Pública, Social y Cooperativa, 31, 47-84. 
BANCO DE ALIMENTOS DE ASTURIAS: www.bancaliasturias.org (última consulta: 20 de julio de 2014).

BERNER, M. \& O'BRIEN, K. (2004): "The shifting pattern of food security support: food stamp and food bank usage in North California", Nonprofit and Voluntary Sector Quarterly, 33(4), 655-672.

BIELEFELD, W. \& CLEVELAND, W. (2013): "Faith-based organizations as service providers and their relationship to government", Nonprofit and Voluntary Sector Quartely, 42(3), 468-494.

CAI, X., CHEN, J., XIAO, Y. \& XU, X. (2010): "Optimization and coordination of fresh product supply chains with freshness-keeping effort", Production and Operation Management, 19(3), 261-278.

CONSEJERÍA DE EMPLEO Y MUJER DE LA COMUNIDAD DE MADRID (2009): "Quiero montar una organización sin ánimo de lucro", Cuadernos de Orientación para el Emprendimiento, №. 29, Madrid.

COQUE, J., GONZÁLEZ TORRE, P.L. \& TORRES VALDAVIDA, C. (2012): "Los bancos de alimentos: Estudio de un caso en España". En: VII Congreso RULESCOOP (Red Universitaria Eurolatinoamericana en Estudios Cooperativos y de Economía Social), Economía social: identidad, desafíos y estrategias, Valencia y Castellón, 5-7 septiembre.

DAPONTE, B.O. \& BADE, S. (2006): "How the private food assistance network evolved: interactions between public and private responses to hunger", Nonprofit and Voluntary Sector Quarterly, 35(4), 668-690.

DAVIS, B. \& TARASUK, V. (1994): "Hunger in Canada", Human Values, 11, 57-58.

DÍEZ, E.J. (2013): "Investigación-Acción participativa: el cambio cultural con la implicación de los participantes", Revista Electrónica Interuniversitaria de Formación del Profesorado, 16 (3), 115-131.

EL PAÍS (2014): "Aumenta el número el número de españoles que recurre a Cáritas en Alicante", 19 de junio (www.elpais.com).

EQUIPO DE ESTUDIOS CÁRITAS ESPAÑOLA (2013): VIII Informe de la Realidad Social, Cáritas Española, Madrid.

FAO (2011): Food Loss Reduction Strategy, Food and Agriculture Organization of the United Nations, Roma.

FEEDING AMERICA (2011): "Food banks: Hunger's New Staple". Research Brief. A report on Visitation Patterns and Characteristics of Food Pantry Clients in the United States in 2009" Chicago, http://feedingamerica.org (última consulta: 18 de junio de 2014).

FESBAL (Federación Española de Bancos de Alimentos): www.fesbal.org (última consulta: 18 de abril de 2015).

FOESSA (2014): VIII Informe sobre exclusión y desarrollo social en España, Fundación de Estudios Sociales y de Sociología Aplicada, Madrid. 
FORD, J., LARDEAU, M., BLACKETT, H., CHATWOOD, S. \& KURSZEWSKI, D. (2013): “Community food program use in Inuvik, Northwest Territories", BMC Public Health, 13, 970.

FUNDACIÓN LUIS VIVES (2012): Anuario del Tercer Sector de Acción Social en España, Fundación Luis Vives, Madrid.

FUNDACIÓN LUIS VIVES (2009): "Los retos del tercer sector ante la crisis", VI Foro Tercer Sector, www.fundacionluisvives.org (última consulta: 14 de junio de 2014).

GONZÁLEZ-TORRE, P.L., COQUE, J. \& ÁLVAREZ ÁLVAREZ, E. (2013): "Diferencias operativas de los bancos de alimentos: el caso español". En: XXIII edición del Congreso Nacional de la Asociación Científica de Economía y Dirección de la Empresa (ACEDE), Málaga, 15-17 septiembre.

GONZÁLEZ-TORRE, P.L. \& COQUE, J. (2015): "How is a food bank managed? Different profiles in Spain", Agriculture and Human Values, DOI 10.1007/s10460-015-9595-x.

HANDFORTH, B., HENNINK, M. \& SCHWARTZ, M. (2013): "A qualitative study of nutrition-based initiatives at selected food Banks in the feeding America network", Journal of the Academy of Nutrition and Dietetics, 113(3), 411-415.

INE (2013): Encuesta de Condiciones de Vida, Instituto Nacional de Estadística, Madrid.

INE (2010): Encuesta de Población Activa, Instituto Nacional de Estadística, Madrid.

JIMÉNEZ LARA, A. (1999): "El estudio sobre el sector no lucrativo en España”, http://usuarios.discapnet.es/ajimenez/tercer_sector/snl.htm (última consulta: 14 de junio de 2014).

JUNTA DE CASTILLA Y LEÓN (2014): "Características del voluntariado en servicios sociales" http://www.jcyl.es/web/jcy//binarios/956/888/Caracteristicas_del_voluntariado_en_Servicios_Sociales.pdf ?blobheader=application/pdf\%3Bcharset\%3DUTF-8\&blobheadername1=CacheControl\&blobheadername2=Expires\&blobheadername3=Site\&blobheadervalue1=must revalidate\%2Cpost-check\%3D0\%2Cpre-check\%3D0\&blobheadervalue2=0\&blobheadervalue3=JCYL_S erviciosSociales\&blobnocache=true (última consulta: 20 de julio de 2014).

KAPUCU, N., HEALY, B. \& ARSLAN, T. (2011): "Survival of the fittest: Capacity building for small nonprofit organizations", Evaluation and Program Planning, 34, 236-245.

LA NUEVA ESPAÑA (2013): "El Banco de Alimentos advierte del gran aumento de niños en riesgo de exclusión", 11 de diciembre (www.Ine.es).

LAMPKIN, L. \& BORIS, E. (2002): "Nonprofit organization data: what we have and what we need", America Behavioral Scientist, 45, 1675-1715.

LAMPKIN, L. \& SUMARIWALLA, R. (1999): "Now that we have the data, can we use them? Assessing the quality of the IRS Form 990 data". In: $28^{\text {th }}$ annual ARNOVA Conference, Washington, DC.

LAPARRA, M. \& ERANSUS, B. (2008): Exclusión social en España: un espacio diverso y disperso en extensa transformación, Fundación Fomento de Estudios Sociales y de Sociología Aplicada FOESSA, Madrid. 
MONTERO SIMÓ, M. (2010): "La regulación de las entidades sin fines lucrativos en Estados Unidos. Especial referencia a su tratamiento fiscal", Crónica Tributaria, 135/2010, 145-177.

PITA FERNÁNDEZ, S. \& PÉRTEGAS DÍAZ, S. (2002): "Investigación cuantitativa y cualitativa", Cad Aten Primaria, 9, 76-78.

RUIZ OLABUÉNAGA, J. (2001): "El sector no lucrativo en España", CIRIEC-España, Revista de Economía Pública, Social y Cooperativa, 37, 51-78.

SCHENEIDER, F. (2013): "The evolution of food donation with respect to waste prevention", Waste Management, 33, 755-763.

SOLAK, S., SCHERRER, C. \& GHONIEM, A. (2012): "The stop-and-drop problem in nonprofit food distribution networks", Annals of Operations Research, 1-20.

STARKEY, L.J. (1994): "An evaluation of emergency food bags", Diet Association, 55, 175-178.

STARKEY, L.J., GRAY-DONALD, K., KUHNLEIN, H.V. (1999): "Nutrient intake of food bank users is related to frequency of food bank use, household size, smoking, education and country of birth", The Journal of Nutrition, 129, 883-889.

TARASUK, V.S. \& BEATON, G.H. (1999): "Household food insecurity and hunger among families using food Banks", Canadian Journal of Public Health, 90(2), 109-113.

TARASUK, V.S. \& EAKIN, J.M. (2003): "Charitable food assistance as symbolic gesture: an ethnographic study of food banks in Ontario", Social Science \& Medicine, 56, 505-1515.

TARASUK, V.S. \& EAKIN, J.M. (2005): "Food assistance through "surplus" food: Insights form an ethnographic study of food bank", Agriculture and Human Values, 22, 177-186.

TERON, A.C. \& TARASUK, V.S. (1999): "Charitable food assistance: What are food bank users receiving?", Revue Canadienne de Santé Publique, 90(6), 382-384.

TOTTEN, V., PANACEK, E. \& PRICE, D. (1999): "Basic of research (part 14). Survey research methodology: designing the survey instrument", Air Medical Journal, 18(1), 26-34.

VIDAL, P. (2008): "La crisis y el tercer sector: una oportunidad para la transformación social", Colección Debates OTS, 9, Consejo Asesor de Investigación del OTS. 
